\title{
A Field Study on the Influence of Verticillium dahliae and Pratylenchus penetrans on Gas Exchange of Potato
}

\author{
Ibrahim A. M. Saeed, Ann E. MacGuidwin, Douglas I. Rouse, and Chris Malek, Department of Plant Pathology, \\ University of Wisconsin, Madison 53706
}

\begin{abstract}
Saeed, I. A. M., MacGuidwin, A. E., Rouse, D. I., and Malek, C. 2007. A field study on the influence of Verticillium dahliae and Pratylenchus penetrans on gas exchange of potato. Plant Dis. 91:1531-1535.

Field experiments were conducted for three consecutive years to study the effects of low populations of Verticillium dahliae and Pratylenchus penetrans on leaf gas exchange of Russet Burbank potato. Treatments were $P$. penetrans, V. dahliae, the combination of the nematode with the fungus, and a no-pathogen control. Gas exchange was measured nondestructively on young, fully expanded, asymptomatic leaves one to three times per week starting the ninth week after planting. Infection with either pathogen alone had little or no effect on leaf gas exchange parameters. However, co-infection by both pathogens resulted in reduced leaf light use efficiency (mole of $\mathrm{CO}_{2}$ fixed per mole of photon), lower leaf stomatal conductance, lower leaf water use efficiency (mole of $\mathrm{CO}_{2}$ fixed per mole of water used), and increased intercellular $\mathrm{CO}_{2}$ compared with the no-pathogen control. These effects, additive relative to the impact of each pathogen alone, were first observed 9 weeks after inoculation in the first 2 years of the study and 15 weeks after inoculation in the third year.
\end{abstract}

Additional keywords: leaf water potential, photosynthesis, potato early dying

Potato early dying (PED) disease is widely spread throughout the potatoproduction regions of North America (14). The disease is caused by the soilborne fungus Verticillium dahliae (Kleb.) and is exacerbated by the nematode Pratylenchus penetrans (Cobb) Filipjev \& Schuurmans Stekhoven (15). Infection of potato by $V$. dahliae induces water stress and wilting and, with sufficient colonization of the vascular system, premature leaf senescence $(5,10-12,14)$. Infection of potato by both $V$. dahliae and $P$. penetrans, even at low inoculum levels, accelerates leaf senescence. With controlled inoculations in the growth chamber, leaves of plants infected with both pathogens had a life span of 22 days compared with 44 days for plants infected with the fungus only and 49 days for noninfected control plants (18).

In addition to foliar symptom expression, combined infection by $V$. dahliae and $P$. penetrans reduced gas exchange $(17,18)$ and yield (10-12) and lowered tuber quality (10) when population densities of the nematode and the fungus were lower than population densities previously shown to cause disease individually. The reduction

Corresponding author: A. E. MacGuidwin

E-mail: aem@plantpath.wisc.edu

Accepted for publication 8 June 2007.

doi:10.1094/PDIS-91-12-1531

(C) 2007 The American Phytopathological Society in tuber yield of potato infected with $V$. dahliae has been attributed to both the limited amount of light intercepted by a defoliated and stunted canopy (2) and to the reduced photosynthetic efficiency of the remaining leaves (3). Reduced interception of radiation accounted for about $67 \%$ and reduced photosynthetic efficiency accounted for about $33 \%$ of yield loss of Russet Burbank potato caused by V. dahliae in growth-chamber studies (3). Three phases of disease were evident in experiments using controlled inoculation $(3,18)$ : a latent phase, when plants were infected but exhibited no symptoms; a local phase, when symptoms were apparent on some but not all leaves; and a systemic phase, when symptoms were detectable even in new leaves. Potato plants infected with both $P$. penetrans and $V$. dahliae reach the systemic phase of disease faster than those infected with the fungus alone $(5,10$, 13,18).

Measures of gas exchange provide a sensitive and early means to determine when leaves are compromised due to infection by $V$. dahliae and nematodes. Under growth-chamber conditions, Bowden and Rouse $(2,3)$ found that infection of Russet Burbank potato by $V$. dahliae reduced carbon assimilation, stomatal conductance, and transpiration before the onset of visual symptoms of senescence. In similar experiments, Saeed et al. $(17,18)$ documented a synergistic interaction between $V$. dahliae and $P$. penetrans for gas exchange of Russet Burbank potato and described stomatal and nonstomatal limitations to photosynthesis associated with local and systemic phases of the disease, respectively (20).

The influence of $V$. dahliae on gas exchange has been studied in the field for potato (8) and other crops $(7,16)$, but only one field study has considered root lesion nematodes. Gent et al. (6) found that both $V$. dahliae and $P$. penetrans reduced gas exchange of 'Superior' potato grown in microplots, and these effects were mitigated by compost amendments. They concluded that the physiological profile of potato infected by both pathogens was similar to that induced by either pathogen alone. Root lesion nematodes are common in potato-production areas and including their effects provides context to field experiments. The objective of our study was to determine whether $P$. penetrans alters the extent of gas exchange effects caused by $V$. dahliae on potato under field conditions and to test whether the synergistic decrease in gas exchange observed under controlled condition can be found in the field.

\section{MATERIALS AND METHODS}

Field plot preparation and establishment. Field studies were conducted for three consecutive years (1993 to 1995) at Hancock Agricultural Research Station near Hancock, WI on a Plainfield loamy sand soil (92\% sand, $5 \%$ silt, $3 \%$ clay, and $<1 \%$ organic matter). The sites were fumigated in fall 1994 and in spring 1993 and 1995 with metham-sodium at 561 liters/ha using a ground rig applicator. Potato cv. Russet Burbank was planted on 13 May 1993, 3 May 1994, and 28 April 1995 at a rate of $1,680 \mathrm{~kg} / \mathrm{ha}$ and grown according to standard cultural practices. Plots were irrigated with a center pivot as needed. Meteorological data for the study site for the 3 years were obtained from the Hancock weather station, located about $400 \mathrm{~m}$ from the study site (Table 1). A common experimental design was used each year, with one initial population density of $P$. penetrans, one initial density of $V$. dahliae, the fungus and the nematode together, and a no-pathogen control. The experimental design was a randomized complete block with five replicates in 1993 and six replicates in 1994 and 1995. Each replicate consisted of four rows, 6.1-m long, and data were collected from the inner two rows. The within-row spacing of plants 
was $30 \mathrm{~cm}$, resulting in approximately 20 plants per row.

Inoculum preparation and inoculation. The $V$. dahliae inoculum was grown on sterilized rye seed (17). After the field plots had been prepared and marked for the positions of potato rows, $V$. dahliae inoculum was spread over the appropriate rows in an area $91 \mathrm{~cm}$ wide and immediately rototilled to a depth of $20 \mathrm{~cm}$. The inoculum contained $6.3 \times 10^{3}, 7.0 \times 10^{4}$, and $13 \times 10^{5}$ propagules/g of ground rye seed in 1993, 1994, and 1995, respectively. The inoculum density was $3.6,4.0$, and 4.2 propagules/g of soil in 1993, 1994, and 1995 , respectively, as determined by plating on Sorenson's NPX medium (4).

The nematode inoculum was prepared in water suspension (11) in a total volume of 2 liters which was mixed with 40 liters of steam-pasteurized Plainfield loamy sand soil. The infested soil was divided into 1liter batches and placed into plastic bags. Potato tubers were planted by machine, but the rows were left open so the nematode inoculum could be added. Soil containing the $P$. penetrans inoculum, portioned for a single row, was poured out of plastic bags evenly down the rows in a band over the seed pieces and the seed row was covered using a disk coulter. Each row in the nematode and the nematode-plus-fungus treatments received $2.6 \times 10^{5}$ nematodes in 1993 and 1994 and $3.1 \times 10^{5}$ nematodes in 1995 , spread evenly down the length of the row.

Pathogen assays. At 11 weeks after planting in 1993 and 1994 and at 15 weeks after planting in 1995, plants were destructively sampled to assess $V$. dahliae in stems and $P$. penetrans in roots. Stem colonization by $V$. dahliae was determined from a 3- to 5-cm piece of the main stem collected $1 \mathrm{~cm}$ above the soil line. Main stems were immersed in $10 \% \mathrm{NaOCl}$ for $30 \mathrm{~s}$ and then rinsed in sterile distilled water for $1 \mathrm{~min}$. Segments from main stems were cut, wrapped in parafilm, and crushed in a plant press. A $0.1-\mathrm{ml}$ aliquot of the sap collected in the parafilm was spread onto Sorensen's NPX medium (9). The petri plates were incubated in the dark at $24^{\circ} \mathrm{C}$ for 2 weeks before the plates were observed using a stereomicroscope and the CFU counted. The roots from each hill were cut into 2-cm-long pieces and mixed, and a 5-g subsample was incubated for 48 $\mathrm{h}$ on a Baermann funnel to recover nematodes (5). P. penetrans were viewed using a stereomicroscope and counted.

Canopy ratings for symptom expression. Canopy ratings were taken 11 to 15 weeks after planting in 1993 and 1994 to assess disease symptom development. Ratings were determined by placing a $1-\mathrm{m}^{2}$ grid, divided into 100 cells, above the plot and counting the number of cells showing at least $50 \%$ green foliage. In 1995, canopy rating was measured using a light bar (1-m silicon pyrenometer; Li-Cor Inc., Lincoln, NE). Incident light above canopy and light transmitted through the canopy were measured and the percent light transmitted was calculated as an indicator of canopy ground coverage. Three readings per plot were taken with the light bar and averages were used to calculate the percent light transmitted.

Gas exchange and leaf water potential measurements. Gas exchange measurements were carried out one to three times per week starting the ninth week after planting and continued for 5 or 7 weeks in the 1993 and 1994 experiments, respectively. In 1995, measurements were collected only during the 15 th and 16th weeks after planting. All gas exchange measurements were taken on the youngest, fully expanded, asymptomatic leaves of three randomly selected plants using a LI-COR 6200 portable photosynthesis system (LiCor, Inc.). Photosynthesis measurements usually were collected between 9:00 a.m. and 2:00 p.m. on days when the skies were clear and the light intensities were above saturation $\left(>1,200 \mu \mathrm{mol}\right.$ photon $\left.\mathrm{m}^{-2} \mathrm{~s}^{-2}\right)$. Leaf light use efficiency (LUE; mole of $\mathrm{CO}_{2}$ fixed per mole of photon), water use efficiency (WUE' mole of $\mathrm{CO}_{2}$ fixed per mole of water used), stomatal conductance $\left(\mathrm{g}_{\mathrm{s}}\right)$, and ambient $\left(\mathrm{C}_{\mathrm{a}}\right)$ and intercellular $\left(\mathrm{C}_{\mathrm{i}}\right)$ $\mathrm{CO}_{2}$ concentrations were measured or calculated by the LI-COR system.

Leaf water potential was measured in the field during the1993 growing season using a pressure chamber (model 3005; SoilMoisture Equipment Corp., Santa Barbara, CA) on leaves studied for gas exchange. To avoid moisture loss from leaves, the terminal leaf was sealed in a plastic bag containing a damp piece of paper towel immediately after cutting. The terminal leaflet and a $1-$ to $3-\mathrm{cm}$ piece of petiole were excised with a razor blade.
The petiole was placed through a custommade silicon rubber seal (RTV-11; General Electric, Waterford, NY) with the hole molded in the shape of a potato petiole. The end point was reached when the first drop of water appeared on the excised end of the leaf petiole. A magnifying lens was used to aid in detecting the end point.

Tuber yield and quality. Plots were harvested by machine on 28 September, 1993, 15 September, 1994, and 29 September, 1995. Tubers were sized, weighed, and graded mechanically. Tubers were culled for unacceptable shape, mechanical damage, scab, and soft rot. The specific gravity of tubers was measured using a potato hydrometer.

Statistical analysis. Data collected for symptom expression were analyzed by repeated measure analysis of variance (ANOVA) for a completely randomized design (SAS Inc., Cary, NC). Least square means of treatments were compared. Gas exchange, leaf water potential, stem colonization, nematode counts, total yield, percent culls, and specific gravity data were analyzed using SAS procedure GLM as a one-way ANOVA. Least significant differences for comparing treatment means also were calculated according to the GLM procedure of SAS.

\section{RESULTS}

Measures of gas exchange distinguished pathogen treatments from the control at 9 and 13 weeks after planting in 1993, at 13 weeks after planting in 1994, and at 15 weeks after planting in 1995 (Table 2). Visual inspection of the potato canopy revealed enhanced senescence of plots infested with both $P$. penetrans and $V$. dahliae $(P<0.05)$ at 13 and 14 weeks after planting in 1994, but did not detect any differences among treatments in 1993 and 1995 (data not shown). There was a consistent trend for reduced canopy scores by experimenters and machine-measured indicators of gas exchange for the pathogen treatment compared with controls on other dates (data not shown); however, the data were not statistically significant.

In 1993, all physiological measures indicated treatment effects, but comparisons among individual treatments varied according to measure. At 9 weeks after planting, LUE in all pathogen treatments differed from the control, with the Verticillium-

Table 1. Soil test results of the experimental plots, air temperature, precipitation, irrigation, and solar radiation in 1993, 1994, and 1995

\begin{tabular}{|c|c|c|c|c|c|c|c|c|c|}
\hline Year & pH & $\mathbf{P}(\mathbf{p p m})$ & $\mathbf{K}(\mathbf{p p m})$ & OM $(\%)^{\mathbf{a}}$ & $\begin{array}{c}\text { Seed rate } \\
(\mathrm{cwt} / \mathrm{a})\end{array}$ & Temp. $\left({ }^{\circ} \mathbf{C}\right)^{b}$ & Prcp. $(\mathrm{mm})^{\mathrm{c}}$ & $\begin{array}{c}\text { Irrigation } \\
(\mathbf{m m})^{d}\end{array}$ & $\begin{array}{c}\text { Solar rad. } \\
\left(\mathrm{W} / \mathbf{m}^{2}\right)^{\mathrm{e}}\end{array}$ \\
\hline 1993 & 6.4 & 120 & 78 & 0.6 & 15 & 17.2 & 674 & 174 & 200 \\
\hline 1994 & 6.7 & 125 & 88 & 0.8 & 15 & 18.4 & 257 & 354 & 236 \\
\hline 1995 & 5.5 & 134 & 105 & 1.0 & 15 & 18.3 & 341 & 313 & 226 \\
\hline
\end{tabular}

a Organic matter.

b Daily air temperature averaged for the growing season.

c Total seasonal precipitation (rainfall).

d Total seasonal irrigation.

e Daily solar radiation averaged for the growing season. 
only treatment most reduced (Table 2). Stomatal conductance also was decreased for all pathogen treatments relative to the control and intercellular $\mathrm{CO}_{2}$ was lower for all except the Verticillium-only treatment (Table 2). There was no difference among treatments for WUE at 9 weeks after planting, except the nematode-only treatment, which was increased. At 13 weeks after planting, measures of LUE and stomatal conductance showed the pathogencombination treatment to be different from the control and nematode-only treatments. At this time, intercellular $\mathrm{CO}_{2}$ levels distinguished the combination treatment from all other treatments. WUE of the combination treatment was decreased compared with the control and the Verticillium-only treatments.

In 1994, the only measure that distinguished treatments was LUE (Table 2). At 13 weeks after planting, LUE for the nematode-only and combination treatment was lower than the Verticillium-only or control treatments. There was a tendency for reduced stomatal conductance for the combination treatment compared with the control, consistent with the other years. Contrary to other years, there was no indication of elevated intercellular $\mathrm{CO}_{2}$ and, by contrast, WUE was increased.

In 1995, data were collected at 15 weeks after planting, the same day of the year as for 13 weeks after planting in 1993. The Verticillium-plus-nematode treatment was not different from the Verticillium-only treatment for any measure, but was impaired for LUE, stomatal conductance, and WUE relative to the nematode-only and control treatments (Table 2). One week later, 30 days before mechanical vine killing, the combination treatment showed significant impairment in the gas exchange measures relative to the control and single pathogen treatments.

In 1993, leaf water potential was significantly reduced $(P=0.05)$ in the $V$. dahiae and combination treatments for most sampling dates (Fig. 1). The effects of the fungus and the fungus-plus-nematode treatments on leaf water potential were strongest during the 10th to 12 th weeks after planting. Solitary infection by $P$. penetrans had no effect on leaf water potential except during weeks 11 to 12 after planting, when a reduction was observed.

Pathogen assays showed that the intended treatments were not conserved for the duration of the experiment (Table 3).

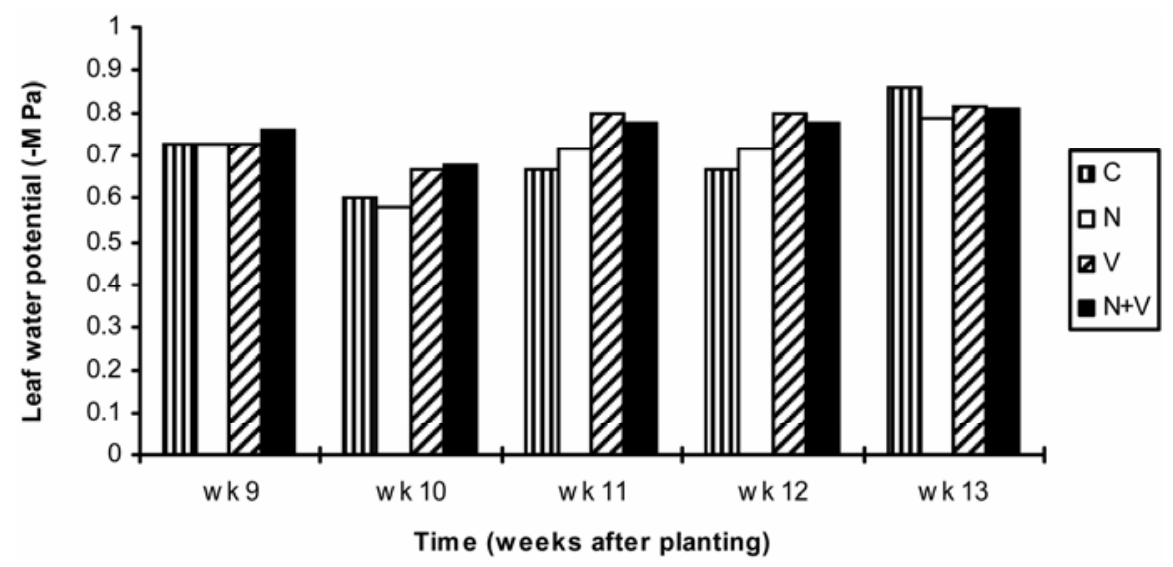

Fig. 1. Leaf water potential (-MPa) of young asymptomatic leaves under control (C), nematode $(\mathrm{P})$, Verticillium (V), and nematode and Verticillium $(\mathrm{P}+\mathrm{V})$ treatments in week 9 through week 13 in 1993. Least square differences between treatments were $0.440,0.020,0.001,0.089$, and 0.230 for weeks 9 , $10,11,12$, and 13 , respectively.

Table 2. Gas exchange data of young symptomless leaves of control potato Russet Burbank plants and plants inoculated with Pratylenchus penetrans, Verticillium dahliae, or both P. penetrans and V. dahliae in experiments conducted in 1993, 1994, and 1995a

\begin{tabular}{|c|c|c|c|c|c|}
\hline \multirow[b]{3}{*}{ Treatment $^{b}$} & \multicolumn{5}{|c|}{ Weeks after planting } \\
\hline & \multicolumn{2}{|c|}{1993} & \multicolumn{2}{|c|}{1994} & \multirow{2}{*}{$\begin{array}{c}1995 \\
\text { Week } 15\end{array}$} \\
\hline & Week 9 & Week 13 & Week 9 & Week 13 & \\
\hline \multicolumn{6}{|l|}{ Light use efficiency } \\
\hline Control & 0.012 & 0.011 & 0.011 & 0.012 & 0.019 \\
\hline Pratylenchus $(\mathrm{P})$ & 0.011 & 0.009 & 0.012 & 0.007 & 0.015 \\
\hline Verticillium $(\mathrm{V})$ & 0.010 & 0.008 & 0.013 & 0.010 & 0.012 \\
\hline$P+V$ & 0.011 & 0.007 & 0.013 & 0.008 & 0.007 \\
\hline$P \leq$ & 0.01 & 0.01 & 0.17 & 0.02 & 0.16 \\
\hline $\operatorname{LSD}_{0.05}$ & 0.001 & 0.002 & $\ldots$ & 0.003 & 0.007 \\
\hline \multicolumn{6}{|c|}{ Stomatal conductance $\left(\mu \mathrm{mol} \mathrm{m}{ }^{-2} \mathrm{~s}^{-1}\right)$} \\
\hline Control & 0.46 & 0.37 & 0.68 & 0.38 & 0.56 \\
\hline Pratylenchus $(\mathrm{P})$ & 0.38 & 0.30 & 0.64 & 0.32 & 0.50 \\
\hline Verticillium $(\mathrm{V})$ & 0.34 & 0.21 & 0.65 & 0.41 & 0.31 \\
\hline$P+V$ & 0.39 & 0.21 & 0.73 & 0.32 & 0.22 \\
\hline$P \leq$ & 0.01 & 0.01 & 0.51 & 0.28 & 0.01 \\
\hline $\mathrm{LSD}_{0.05}$ & 0.05 & 0.07 & $\ldots$ & $\ldots$ & 0.17 \\
\hline \multicolumn{6}{|c|}{ Intercellular $\mathrm{CO}_{2}(\mathrm{ppm})$} \\
\hline Control & 237.7 & 241.4 & 224.8 & 258.4 & 262.6 \\
\hline Pratylenchus $(\mathrm{P})$ & 222.6 & 246.8 & 221.9 & 257.1 & 263.1 \\
\hline Verticillium $(\mathrm{V})$ & 237.9 & 242.7 & 216.6 & 258.6 & 255.0 \\
\hline$P+V$ & 225.7 & 267.2 & 227.0 & 248.3 & 259.2 \\
\hline$P \leq$ & 0.01 & 0.01 & 0.47 & 0.61 & 0.95 \\
\hline $\mathrm{LSD}_{0.05}$ & 9.35 & 15.3 & $\ldots$ & $\ldots$ & $\ldots$ \\
\hline \multicolumn{6}{|l|}{ Water use efficiency } \\
\hline Control & 0.0027 & 0.0020 & 0.0017 & 0.0019 & 0.0018 \\
\hline Pratylenchus $(\mathrm{P})$ & 0.0029 & 0.0017 & 0.0019 & 0.0015 & 0.0015 \\
\hline Verticillium $(\mathrm{V})$ & 0.0026 & 0.0018 & 0.0020 & 0.0017 & 0.0014 \\
\hline$P+V$ & 0.0027 & 0.0016 & 0.0019 & 0.0017 & 0.0012 \\
\hline$P \leq$ & 0.03 & 0.03 & 0.06 & 0.11 & 0.01 \\
\hline $\mathrm{LSD}_{0.05}$ & 0.0002 & 0.0002 & $\ldots$ & $\ldots$ & 0.0004 \\
\hline
\end{tabular}

${ }^{a}$ Each value is a mean of either 18, 36, or 54 measurements depending on the number of times measurements were taken in a particular week.

${ }^{\text {b }} P$ value based on a one-way analysis of variance and $\mathrm{LSD}=$ least significant difference.

${ }^{\mathrm{c}}$ In 1995, 15 weeks after planting was the same day of the year as 13 weeks after planting in 1993. 
Verticillium spp. were detected where they were not applied. Contamination of nonematode plots by $P$. penetrans was detected at only a low level in 1993. Population densities of $P$. penetrans tended to be lower in plots infested with both nematodes and V. dahliae; however, the differ-

There was a significant effect of pathogen treatments on yield in 1 of 3 years (Table 4). In 1995, combined infection by $P$. penetrans and $V$. dahliae reduced total yield compared with the control, whereas the single-pathogen treatments did not. Loss due to cullage was not influenced by treatment (data not shown) and there was a trend for reduced specific gravity in tubers from all pathogen treatments relative to the control.

\section{DISCUSSION}

Physiological responses of potato plants to infection by $V$. dahliae and $P$. penetrans provided a nonbiased means to monitor disease under field conditions. Our earlier studies $(13,17-19)$ using controlled environmental conditions in a growth chamber showed synergistic foliar symptom expression, reduced yield, and impaired gas exchange for jointly infected potato plants at population densities of the nematode and the fungus too low to cause disease individually. This study was conducted in the field using controlled inoculum with variable environmental conditions. The 3 years ences were not statistically significant.

of the study were different in terms of solar radiation, precipitation, and temperature. Differences between the 3 years of study observed for the extent of infection, disease symptoms, gas exchange, and potato yield can be attributed partially to variation in these climatic conditions. In an earlier field study (10), we reported similar variation in the interaction of $P$. penetrans and $V$. dahliae over 2 years. Francl and coworkers (5) related the severity of PED and reduction in potato yield to elevated temperature and reduced soil moisture content. The Russet Burbank cultivar used in our studies was shown to be more sensitive to $V$. dahliae under water-deficit stress conditions than five other potato cultivars (1), a condition that occurs intermittently even under irrigation.

Co-infection by $P$. penetrans and $V$. dahliae significantly reduced leaf light use efficiency for all 3 years of the experiment and stomatal conductance and water use efficiency for 2 of the 3 years. The timing of symptoms resembled that found by Bowden and Rouse (3) for infection with high inoculum levels of $V$. dahliae. This result is consistent with our previous work (13,17-19) and studies conducted using other potato cultivars grown under different environmental conditions $(11,12,15)$. The effects of $V$. dahliae and $P$. penetrans on LUE were additive in this study; disease in plants jointly infected by both early dying pathogens was predictive from their

Table 3. Number of Pratylenchus penetrans recovered from $1 \mathrm{~g}$ of fresh roots of potato and the proportions of potato stems positive for Verticillium dahliae from plots noninfested or infested with the fungus, the nematode, or both in 1993, 1994, and 1995

\begin{tabular}{lcc}
\hline Treatment & P. penetrans/g of roots & Stems positive for $\boldsymbol{V}$. dahliae $(\%)$ \\
\hline 1993 & 0 & $*$ \\
Control & $46 \pm 24$ & $*$ \\
P. penetrans $(\mathrm{P})$ & $1 \pm 1$ & $47 \pm 11$ \\
V. dahliae $(\mathrm{V})$ & $21 \pm 9$ & $51 \pm 8$ \\
P + V & 0 & $14 \pm 8$ \\
1994 & $20 \pm 3$ & $28 \pm 13$ \\
Control & 0 & $46 \pm 13$ \\
P. penetrans $(\mathrm{P})$ & $18 \pm 12$ & $49 \pm 8$ \\
V. dahliae $(\mathrm{V})$ & 0 & $29 \pm 18$ \\
P + V & $29 \pm 7$ & $37 \pm 19$ \\
1995 & 0 & $67 \pm 9$ \\
Control & $91 \pm 34$ & $78 \pm 13$ \\
P. penetrans $(\mathrm{P})$ & & \\
V. dahliae $(\mathrm{V})$ & & \\
P + V & &
\end{tabular}

a Treatment mean \pm standard error. Roots and stems were sampled at 11 weeks after planting (WAP) in 1993, at 11 WAP in 1994, and at 15 WAP in $1995 ; *=$ not collected at 11 WAP.

Table 4. Yield and specific gravity for tubers of control potato plants and plants inoculated with Pratylenchus penetrans, Verticillium dahliae, or both in 1993, 1994, and 1995

\begin{tabular}{lcccccc}
\hline & \multicolumn{3}{c}{ Yield (t/ha) } & & \multicolumn{2}{c}{ Specific gravity } \\
\cline { 2 - 3 } \cline { 6 - 7 } Treatment $^{\mathbf{a}}$ & $\mathbf{1 9 9 3}$ & $\mathbf{1 9 9 4}$ & $\mathbf{1 9 9 5}$ & & $\mathbf{1 9 9 3}$ & $\mathbf{1 9 9 4}$ \\
\hline Control & 42.77 & 45.52 & 39.12 & & 1.088 & 1.088 \\
P. penetrans $(\mathrm{P})$ & 37.42 & 47.27 & 33.98 & & 1.088 & 1.089 \\
V. dahliae $(\mathrm{V})$ & 36.82 & 46.01 & 36.35 & & 1.087 & 1.088 \\
$\mathrm{P}+\mathrm{V}$ & 35.50 & 49.40 & 24.67 & & 1.087 & 1.087 \\
$P=$ & 0.23 & 0.09 & 0.0001 & & 0.08 & 0.08 \\
$\mathrm{LSD}_{0.05}$ & $\ldots$ & $\ldots$ & 7.01 & & $\ldots$ & $\ldots$ \\
\hline
\end{tabular}

a $P$ value based on a one-way analysis of variance and $\mathrm{LSD}=$ least significant difference. individual effects. Multiyear microplot experiments in Wisconsin (10) and Ohio (11) found the interaction to be synergistic or additive, depending on year. Under growth-chamber conditions, the interaction was synergistic $(13,17)$. These results suggest that the population dynamics of the two pathogens influences their interaction, as moderated by inoculum placement, environmental conditions, or other unidentified factors.

In agreement with Gent et al. (6), we observed a reduction in photosynthesis in plots infested only with $P$. penetrans. Although background contamination of the plots with $V$. dahliae was present, it is reasonable to assume the difference among the treatments was related to the inoculum added because potato grown in control plots also tested positive for $V$. dahliae. Cross-contamination of experimental units with $V$. dahliae, whether microplot or field plot, is a common feature of the multiyear studies that tracked pathogen populations $(10,11)$ and reflects the high capacity of $V$. dahliae for passive dispersal.

In this experiment, leaves of jointlyinoculated plants remained healthy for 4 to 5 weeks, regardless of the number of nematodes present in each plot. After that time, there was a sudden decrease in net photosynthesis relative to the rate of natural senescence. This dramatic onset of physiological symptoms coincides with the time necessary to achieve an increase in nematode-induced stress due to reproduction and to the shift from latent to local infection by $V$. dahliae. The lack of a significant effect of nematode dose given the range of nematode densities used in the three experiments suggests that the onset of symptoms was related to the activity of the fungus. The level of the Verticillium sp. used in our experiment was sufficient to cause extensive colonization of the vascular system by the fungus by the end of the experiment, but not sufficient to impair gas exchange in the absence of the nematode, indicating that infection by $P$. penetrans altered plant response to $V$. dahliae infection. These results corroborate findings from growthchamber experiments reported by Rotenberg et al. (13).

This study used physiological data to confirm field-based studies showing an interaction of $V$. dahliae and $P$. penetrans for symptom expression of Russet Burbank potato. A widely recognized problem with visual ratings of disease symptoms is that PED disease is easily confused with normal senescence of older leaves (15). In our study, gas exchange measurements of the youngest leaves showed reductions that often occurred before noticeable symptoms and were consistent with visual symptoms seen on older leaves. Gas exchange may provide a useful tool for early and reliable detection of PED disease for irrigated potato. 


\section{ACKNOWLEDGMENTS}

This research was supported by USDA-ARS Competitive Grant no. 58-1275-1-136 and USDANRI Competitive Grant no. 92-37302-7609.

\section{LITERATURE CITED}

1. Arbogast, M., Powelson, M. L., Cappaert, M. R., and Watrud, L. S. 1999. Response of six potato cultivars to amount of applied water and Verticillium dahliae. Phytopathology 89:782788 .

2. Bowden, R. L., and Rouse, D. I. 1991. Effects of Verticillium dahliae on gas exchange of potato. Phytopathology 81:293-301.

3. Bowden, R. L., and Rouse D. I. 1991. Chronology of gas exchange effects and growth effects of infection by Verticillium dahliae in potato. Phytopathology 81:301-310.

4. Butterfield, E. J., and DeVay, J. E. 1977. Reassessment of soil assays for Verticillium dahliae. Phytopathology 67:1073-1078.

5. Francl, L .J., Rowe, R. C., Riedel, R. M., and Madden, L. V. 1988. Effects of three soil types on potato early dying disease and associated yield reduction. Phytopathology 78:159-165.

6. Gent, M. P. N., LaMondia, J., Ferrandino, F. J., and Elmer, W. H. 1999. The influence of compost amendment or straw mulch on the reduction of gas exchange in potato by Verticillium dahliae and Pratylenchus penetrans Plant Dis. 83:371-376.

7. Hamptom, R. E., Wullschleger, S. D., and Oosterhuis, D. M. 1990. Impact of Verticillium wilt on net photosynthesis, respiration and photorespiration in field-grown cotton (Gossypium hirsutum L.). Physiol. Mol. Plant Pathol. 37:271-280.

8. Haverkort, A. J., Rouse, D. I., and Turkensteen, L. J. 1990. The influence of Verticillium dahliae and drought on potato crop growth. 1. Effects on gas exchange and stomatal behavior of individual leaves and crop canopies. Neth. J. Plant Pathol. 96:273-289.

9. Hoyos, G. P., Zambino, P. J., and Anderson, N. A. 1991. An assay to quantify vascular colonization of potato by Verticillium dahliae. Am. Potato J. 68:727-742.

10. MacGuidwin, A. E., and Rouse, D. I. 1990. Role of Pratylenchus penetrans in the potato early dying disease of Russet Burbank potato. Phytopathology 80:1077-1082.

11. Martin, M. J., Riedel, R. M., and Rowe, R. C. 1982. Verticillium dahliae and Pratylenchus penetrans: Interactions in early dying complex of potato in Ohio. Phytopathology 72:640-644.

12. Riedel, R. M., Rowe, R. C., and Martin, M. J. 1985. Differential interactions of Pratylenchus crenatus, $P$. penetrans, and $P$. scribneri with Verticillium dahliae in potato early dying disease. Phytopathology 75:419-422.

13. Rotenberg, D., MacGuidwin, A. E., Saeed, I. A. M., and Rouse, D. I. 2004. Interaction of spatially separated Pratylenchus penetrans and Verticillium dahliae on potato measured by impaired photosynthesis. Plant Pathol. 53:294302.

14. Rowe, R. C., Davis, J. R., Powelson, M. L., and Rouse, D. I. 1987. Potato early dying: Causal agents and management strategies. Plant. Dis. 71:482-489.

15. Rowe, R. C. Riedel, R. M., and Martin, M. J. 1985. Synergistic interaction between Verticillium dahliae and Pratylenchus penetrans in potato early dying disease. Phytopathology 75:412-418

16. Sadras, V. O., Quiroz, F., Echarte, L., Escande, A., and Pereyra, V. R. 2000. Effect of Verticil lium dahliae on photosynthesis, leaf expansion and senescence of field-grown sunflower. Ann. Bot. 86:1007-1015.

17. Saeed, I. A. M., MacGuidwin, A. E., and Rouse, D. I. 1997. Synergism of Pratylenchus penetrans and Verticillium dahliae manifested by reduced gas exchange in potato. Phytopathology 87:435-439.

18. Saeed, I. A. M., MacGuidwin, A. E., and Rouse, D. I. 1997. Disease progress based on effects of Verticillium dahliae and Pratylenchus penetrans on gas exchange in Russe Burbank potato. Phytopathology 87:440-445.

19. Saeed, I. A. M., MacGuidwin, A. E., and Rouse, D. I. 1998. Effect of initial nematode population density on the interaction of Praty lenchus penetrans and Verticillium dahliae on Russet Burbank potato. J. Nematol. 30:100107.

20. Saeed, I. A. M., MacGuidwin, A. E., and Rouse, D. I. 1999. Limitation to photosynthesis in Pratylenchus penetrans- and Verticillium dahliae- infected potato. Crop Sci. 39:13401346. 